\title{
LINGUAGEM AUDIOVISUAL EM SALA DE AULA: NOVOS SUJEITOS, NOVOS OBJETOS E NOVAS PRÁTICAS
}

\author{
Janaina de Jesus Santos ${ }^{*}$ \\ Se eu extinguir quero renascêr \\ Num país que predomina o preto. \\ Adeus! Adeus, en vou morrer! \\ E dêixo êstes versos ao meu país \\ se e que temos o direito de renascer \\ Quero um lugar, onde o preto é feliz.
} (JESUS, [1974])

\begin{abstract}
RESUMO: Neste estudo, visamos, em primeiro lugar, propor o estudo das linguagens verbal, visual e audiovisual no contexto escolar e de sua compreensão como superfície cultural que dá visibilidade para outras existências e outros mundos.Partindo desse objetivo, desenhamos os seguintes objetivos específicos: mapear as potencialidades e limitações do audiovisual como recurso didático; identificar sob que perspectivas pedagógicas essa prática pode ocorrer; oferecer elementos para compreender as possibilidades do uso do audiovisual em sala de aula; e elaborar uma proposta de sequência didática que aborde gêneros discursivos e relações étnico-raciais para a sala de aula de Ensino Fundamental II. Centrando na proposta de sequência didática, podemos afirmar que o diálogo entre a teoria e o cotidiano escolar permite uma visão mais aberta para as linguagens, suas particularidades e suas potencialidades com a finalidade de sensibilizar, contextualizar, exemplificar e a ilustrar conteúdos.
\end{abstract}

PALAVRAS-CHAVE: Gêneros discursivos; Linguagem audiovisual; Relações étnico-raciais; Sequência didática.

\section{Palavras iniciais}

A linguagem audiovisual, como suporte didático-pedagógico, permite a inserção do aluno em distintos contextos, em simulações de situações de uso da linguagem e em contato

\footnotetext{
* Doutora em Linguística e Língua Portuguesa pela Universidade Estadual Paulista Júlio de Mesquita Filho (Unesp). Professor Adjunto da Universidade do Estado da Bahia (Uneb).
} 
com representação de diversas culturas e países, especialmente quando se trata de ensino e aprendizagem de língua estrangeira. Promover atividades pedagógicas com objetos audiovisuais, a exemplo do vídeo e do filme no ensino de língua inglesa, além de ser motivador, permite aos aprendizes se aproximar da língua-alvo em contextos mais próximos do cenário de interação.

Atualmente, observamos em nossa sociedade a explosão na produção e consumo de vídeos na internet e nas redes sociais. Isso demonstra a produtividade desse suporte, ao mesmo tempo em que indica que esses elementos fazem parte do cotidiano dos sujeitos contemporâneos, quer sejam alunos, professores e profissionais em geral.

Há, pois, um vocativo para que professores de línguas estudem essa linguagem e explorem as possíveis congruências de noções e funcionamentos entre o linguístico, o sonoro e o imagético. É sabido que a materialidade dos filmes é imbuída das especificidades do complexo de imagens e sons na produção de uma narrativa. No mesmo sentido, tratase de um potente suporte para os discursos e a cristalização de sentidos sobre os sujeitos e as relações sócio-históricas.

Assim, acreditamos ser relevante trazer contribuições teóricas e metodológicas como uma troca de ideias com os professores interessados, bem como uma tentativa de colaborar com uma área que ainda demanda esforços em estudos e práticas.

Assumindo a importância do estudo das linguagens verbal, visual e audiovisual no contexto escolar e de sua compreensão como superfície cultural que dá visibilidade para outras existências e outros mundos, propomos: 1) mapear as potencialidades e limitações do audiovisual como recurso didático; 2) identificar sob que perspectivas pedagógicas essa prática pode ocorrer; 3) oferecer elementos para compreender as possibilidades do uso do audiovisual em sala de aula; 4) elaborar uma proposta de sequência didática que aborde gêneros discursivos e relações étnico-raciais para a sala de aula de Ensino Fundamental II. 


\section{"Em vez de flores eram livros", vídeos e filmes}

Atualmente, a popularização de recursos tecnológicos e da internet, principalmente em se tratando de dispositivos móveis, faz circular milhões de vídeos ao redor do globo. Nesse contexto, parece necessário que a sala de aula se abra para a pluralidade de linguagens como mais uma linguagem a conhecer e um veículo para a aprendizagem. Isso demanda reflexões sobre as situações de ensino e aprendizagem que ainda tendem a considerar como material didático somente aquele escrito em livros referenciados.

A forma como o professor utiliza o audiovisual no contexto pedagógico depende, em parte, de como ele entende esse processo de transformação e de como ele se sente em relação a isso: se o entende como algo benéfico, que pode ajudar no desenvolvimento do ensino e aprendizagem; ou se ele se sente ameaçado e acuado por essas mudanças.

Entendemos que os objetos pedagógicos surgem das práticas realizadas para resolver as questões colocadas pelo cotidiano. Muitas vezes, os filmes aparecem nas aulas e livros didáticos como recurso para ilustrar um conteúdo, percebendo-o como uma representação da realidade. Pensamos ser necessário colocar em suspense a noção de representação e verdade em favor de uma superfície que tem uma historicidade como objeto cultural e produção da indústria cinematográfica e que revela sobre a existência dos sujeitos.

Ainda que sendo marcadamente uma expressão cultural, o cinema oferece elementos significativos para o entendimento de questões sociais, econômicas e políticas. Trata-se de percebê-lo como representação, leitura e interpretação da realidade e não a realidade em si, ou ainda, como o produto de um momento.

Podemos considerar as características artísticas, estéticas e semiológicas dentro da própria indústria do cinema. Em se tratando de filmes hollywoodianos esses aspectos podem ser centrais para entender valores e crenças políticas, sociais e econômicas mostradas na narrativa (FERRO, 2010).

Problematizar esse uso, considerando os filmes para além de mera ilustração, requer tomá-los como superfície de discursos que possibilitam a reflexão sobre a realidade sóciohistórica e os sujeitos contemporâneos. 
Além de objeto cultural e superfície de discursos, é interessante pensar o filme na dimensão de suporte textual, em que diversos gêneros discursivos ganham visibilidade. Isso trabalha na concepção de que a competência linguística implica considerar o domínio técnico da língua, as condições de produção e interpretação de enunciados em contextos de uso (BAKHTIN, 1997).

Para Bakhtin (2003), os gêneros discursivos são caracterizados pelo conteúdo temático, o estilo e a construção composicional. Esses elementos estão intimamente imbricados na elaboração do enunciado e são determinados pelas condições de seu uso. Ele afirma que os gêneros estão assentados sobre estruturas relativamente estáveis que lhe moldam o perfil para ser de um e não de outro e, ao mesmo tempo, criar uma moldura para que produzam sentidos.

O linguista russo afirma a importância do estilo na identificação dos gêneros do discurso, mas, igualmente, destaca a singularidade do enunciado. Essa singularidade pode ser marcada pela individualidade do falante ou escritor em alguns enunciados.

Nessa mesma direção, o linguista brasileiro Marcuschi (2008) argumenta que os gêneros são imbuídos de particularidades relacionadas a sua existência histórico-social, no sentido de que mudanças culturais, tecnológicas, sociais e/ou históricas repercutem na função do gênero. Em outras palavras, há uma dinâmica própria a comunidades e domínios discursivos que ordenam o funcionamento comunicacional, tanto em conteúdo como em forma dos gêneros discursivos.

Com Bronckart (2006, p. 13) entendemos que

os gêneros de textos constituíam os produtos de configurações de escolhas entre as possíveis, que são momentaneamente estabilizadas pelo uso, escolha que emerge do trabalho que realiza as formações sócio-discursivas para que os textos sejam adaptados às atividades que eles praticam, adaptados a um meio comunicativo dado, eficazes em face a tal aposta social, etc. Em razão desse estatuto, os gêneros mudam necessariamente com o tempo, ou com a história das formações sócio-discursivas. 
Pensando no papel das práticas de linguagem na contribuição e no desenvolvimento das capacidades epistêmicas e praxológicas, perceber o filme e o vídeo como suportes de diversos textos provoca a aproximação entre sujeitos e práticas comunicacionais situados na mesma temporalidade.

Todavia, mesmo se um texto mobilizar unidades linguísticas ou de outras semioses, não constitui em si mesmo uma unidade linguística; suas condições de existência não são da competência do plano linguístico, mas são determinadas pelas práticas que o permitiram existir como unidade de comunicação. Salientamos, com Foucault (2007) que que as condições de existência dos discursos e textos é histórica, podendo ser materializada nos mais diversos suportes e gêneros.

A partir da proposta teórica do estudioso belga, Marcuschi (2008) faz trabalhar a concepção de que os gêneros têm identidade própria e são ordenamentos fortes, que direcionam as escolhas formais e temáticas na produção textual, mostrando como deve se configurar para ser categorizado em tal gênero e não outro. Considera, ainda, a possibilidade de um texto apresentar características de mais de uma classe, sendo guiado pela predominância de elementos para sua categorização. Assim, é importante ter em vista aspectos como suporte, traços e recorrência de conteúdo para identificar os gêneros textuais.

No horizonte da teoria dos gêneros, pensamos que o material didático deve ser concebido e trabalhado em sala de aula guiado por concepções teóricas sobre o processo de ensino-aprendizagem, linguagem e práticas. Isso possibilita que o texto estudado seja compreendido e integrado aos conhecimentos para a vida do educando.

Destacamos que o trabalho com os diversos gêneros na escola requer uma seleção e organização pautadas pelo diálogo com a realidade sócio-histórica dos discentes, pela organização da sociedade, bem como pela criatividade dos sujeitos envolvidos.

Esses princípios e procedimentos estão amparados em conceitos sobre linguagem e prática de ensino-aprendizagem. Ao tratar do ensino de língua estrangeira para fins específicos, Dudley-Evans e St. John (1998) e Hutchinson e Waters (1997) indicam que os 
textos devem: 1) causar impacto no aluno, instigando-o para sua potencialidade; 2) estimular e motivar o discente por meio de desafio, novidade e relação com sua realidade; 3) favorecer os sentimentos de confiança e tranquilidade para participar das atividades; 4) mostrar a relevância do material para a vida do aluno; e 5) possibilitar descobertas e responsabilidade no processo de ensino-aprendizagem.

$\mathrm{Na}$ área de ensino e aprendizagem de língua estrangeira, consideramos, igualmente, o uso para fins comunicativos de modo a envolver os educandos em atividades que possibilitem o engajamento discursivo em práticas sociais por meio da linguagem e, também, a avaliação das metas alcançadas. Ainda no horizonte dessa perspectiva teórica, é crucial incluir o sujeito educando, como participante que traz valores e expectativas sobre sua aprendizagem além de assumir a responsabilidade sobre o processo.

\section{“Quantas coisas eu quiz fazer”}

Desde os anos 1980, o texto tem sido assumido como uma importante unidade de ensino de línguas para os diversos níveis escolares. Como desdobramento, os gêneros textuais assumiram a função de objetos de ensino no arcabouço teórico e nos documentos balizadores da educação básica.

Os Parâmetros Curriculares Nacionais (BRASIL, 1997, 1998) apontam a necessidade de uma prática docente pautada por "projeto", "atividade sequenciada" e "módulo didático", sendo que o primeiro tem a particularidade de ter "um objetivo compartilhado por todos os envolvidos, que se expressa em um produto final em função do qual todos trabalham." (1997, p. 45); a segunda está relacionada a "situações didáticas adequadas para promover" (1997, p. 46) alguma habilidade do educando; e o último é sequência de "atividades e exercícios organizados de maneira gradual" (1998, p. 88).De modo amplo, podemos percebê-los como um conjunto de estratégias e práticas planejadas pelo professor com a finalidade de desenvolver a compreensão sobre uma temática ou situação.

A relevância assumida por essa perspectiva da prática pedagógica tem desdobramento na chamada sequência didática, pedagógica ou de aprendizagem, ela é considerada 
ferramenta didática essencial para o ensino. Kobashigawa et al. (2008) compara a sequência didática com o plano de aula, distinguindo-os pela diversidade de estratégias de aprendizagem e a extensão de várias aulas próprias à sequência. Ela organiza os conhecimentos teóricos a serem didatizados no processo de ensino e aprendizagem (NASCIMENTO, 2009), é exposta à prática para concretizar a aprendizagem (GUIMARÃES et al., 2015) e, também, é concebida como o produto da transposição didática (CHEVALLARD, 1991).

Nessa mesma direção, Rucker (2017, p. 5), citando outros autores, destaca que a sequência didática é produzida na sucessão dos processos de concepção, realização, observação e análise das situações didáticas, cujos objetivos são:

1. Interagir com os obstáculos identificados, elementarizando a dificuldade de maneira a facilitar a apropriação de elementos novos (DOLZ, GAGNON \& VUILLET, 2011).

2. Garantir a presença de dispositivos de apoio que facilitem as capacidades de linguagem do aluno.

3. Contribuir com uma explicação conceitual, uma explicação (BAUTIER; ROCHEX, 1997) e com uma compreensão das operações de linguagem mobilizadas pelo aluno para facilitar o desenvolvimento do controle consciente do comportamento verbal (SCHNEUWLY, 2008).

4. Fazer desaparecer progressivamente as ajudas externas até a devolução completa da tarefa para desenvolver autonomia do aluno.

5. Deixar um espaço de liberdade para o aluno que permita as interações e a construção subjetiva para converter se em ator do seu próprio desenvolvimento da linguagem e da expressão de sua identidade (DOLZ-MESTRE, 2016, p. 246).

A partir dos estudos da linguagem, Machado (1997) afirma que uma sequência didática deve considerar que: a) o processo de ensino e aprendizagem deve centralizar a linguagem por meio dos gêneros e de suas condições de produção; b) as capacidades e as dificuldades dos educandos são orientadores; c) o gênero deve ser estudado em suas diversas características por atividades específicas, de modo a possibilitar sua apropriação; d) há a necessidade da prática no contexto real de comunicação; e e) é importante a articulação da sequência em um projeto de classe que define suas condições de produção. 
Pautando-nos, uma vez mais, nos Parâmetros Curriculares Nacionais de Língua Estrangeira (BRASIL, 1998, p. 54), eles recomendam que seu ensino seja orientado pelo entendimento de língua(gem) como uma "prática social com possibilidades de expressar opiniões, valores, sentimentos, informações oralmente e por escrito".

Partindo do pressuposto de que na sociedade conectada, as linguagens verbal, visual e multimodal estão presentes nas relações cotidianas e são protagonistas do sistema de signos que promovem a produção de sentidos, é necessário refletir sobre as práticas de letramento relacionadas tanto aos usos da escrita como da imagem e seus impactos na vida do educando, com a finalidade de promover o desenvolvimento de múltiplos conhecimentos, habilidades e capacidades para a leitura e a produção. Portanto, a perspectiva de letramento amplia o processo de alfabetização e apresenta novas possibilidades de interação por meio das diversas linguagens (KLEIMAN, 2005).

Diante desse horizonte, acreditamos na potencialidade do uso pedagógico de filmes, para: estimular a criatividade pela participação ativa no processo de aprendizados múltiplos, propiciar o reconhecimento da sensibilidade e das emoções dos educandos, ampliar a apresentação do contexto de conteúdos e abordar interdisciplinarmente um tema.

Moran (1995) ressalta a relação de familiaridade que o audiovisual provoca nos estudantes, pelo fato de a televisão estar presente em muitas casas e representar o momento de lazer e encontro nas famílias de menor poder aquisitivo. Outros pontos positivos do vídeo em relação a outros recursos didáticos são: a capacidade de imitar o mundo, parecendo ser concreto e de conhecimento imediato; a ampliação do alcance aos sentidos; e sua vocação para o envolvimento emocional por meio de elementos visuais e sonoros.

Nessa mesma direção, Santos e Kloss (2010) apontam que o vídeo permite a exposição a diferentes realidades, sociedades, línguas e culturas, de maneira atrativa e prazerosa. Entretanto, é essencial que o uso do audiovisual como recurso pedagógico ultrapasse o nível de novidade nas aulas e seja acompanhado de um planejamento cuidadoso, uma contextualização do filme ou vídeo, uma discussão da temática e/ou do conteúdo e uma proposta avaliativa. 
Os estudos de Silva (2000), Moran, Masetto e Behrens (2006) demonstram que o audiovisual ainda não é trabalhado em suas potencialidades na prática pedagógica, sendo limitado por uma exploração superficial de lazer e entretenimento. Algumas críticas vão na direção de que, muitas vezes, esses recursos são incluídos na aula sem uma contextualização educacional e sem um objetivo pedagógico definido.

Face a esse quadro, Moran (1995) sustenta que o vídeo oferece muito proveito na apresentação de um novo conteúdo, no estímulo à curiosidade e à motivação para o estudo e o aprofundamento pela pesquisa. Nesse sentido, ele aponta algumas situações para o uso do audiovisual: 1) sensibilização no momento de iniciar um novo assunto, sendo indicados vídeos curtos, propagandas, resenhas ou pequenos documentários; 2) ilustração para exemplificar um tópico ou relacionar com a realidade discente, especialmente filmes, entrevistas ou documentários mais longos; 3) simulação de experimento que não pode ser realizado em sala, exemplificando com um documentário; 4) conteúdo de ensino para instruir sobre um tema podendo ter uma abordagem interdisciplinar, sendo indicados tutoriais e entrevistas; 5) produção de discentes e/ou docentes para documentar um evento, transformar outro material ou melhorar a expressão dos estudantes; 6) avaliação do processo de ensino e aprendizagem; 7) vídeo-espelho para incluir alunos e/ou professores no audiovisual e refletir sobre suas qualidades e deficiências; 8) suporte de outras mídias pode incluir tv, computador, etc. para formar uma unidade significativa na apresentação.

Portanto, é imprescindível que o uso do audiovisual esteja inserido em um planejamento com objetivos estabelecidos para alcançar resultados pedagógicos significativos na transposição didática.

\section{"Eu sorri... e despertei"}

Nossa proposta de sequência didática articula-se a uma abordagem de material em linguagem verbal, visual e audiovisual em aula do Ensino Fundamental II. Não apenas pensamos na mudança dos objetos didáticos, mas na mudança na relação pedagógica de 
modo a proporcionar uma aprendizagem mais significativa para a vida do estudante e um posicionamento ativo e responsável por sua aprendizagem.

Junto com ética, saúde, meio ambiente, orientação sexual, trabalho e consumo, a pluralidade cultural é um dos temas transversais propostos pelo Ministério da Educação nos Parâmetros Curriculares Nacionais (BRASIL, 1997). Os temas são questões consideradas importantes e urgentes pelos estudiosos e políticos para fazerem parte da vivência escolar. Eles estão relacionados à compreensão e à construção da "realidade social e dos direitos e responsabilidades relacionados com a vida pessoal e coletiva e com a afirmação do princípio da participação política. Isso significa que devem ser trabalhados, de forma transversal, nas áreas e/ou disciplinas já existentes”.

A pluralidade cultural, assim como os outros, está presente na sociedade, imbricada nas questões contemporâneas e no convívio escolar. Para a abordagem dessas temáticas, o documento federal sugere a elaboração de projetos organizando diversas atividades de dimensão didática. É nessa perspectiva que propomos uma sequência didática que trabalhe linguagens, gênero discursivo e as relações étnico-raciais de nossa sociedade.

Pensamos que o grupo pode desdobrar a questão motriz "qual a contribuição da população negra para a transformação científica e social da sociedade?" em metas como: identificar os recursos expressivos próprios aos gêneros discursivos sinopse e resenha de filme, letra de música, poema e matéria jornalística online; descrever as diferenças entre os suportes livro, hipertexto, imagem, som e audiovisual; elencar especificidades da leitura desses textos; entender o percurso de leitura dos diversos suportes; analisar a produção de sentido desses objetos, na contemporaneidade; e incentivar a produção textual nas linguagens verbal, visual e audiovisual em um projeto de intervenção.

Nesse conjunto, os objetos selecionados evocam conhecimentos das diversas áreas, como linguagens, ciências, história e artes e fazem ecoar a complexidade da realidade, como indicado nos temas transversais.

No primeiro momento, é interessante traçar direcionamentos da leitura para possibilitar uma exploração das especificidades das linguagens e entendimento da composição 
dos elementos verbais, visuais e sonoros. Os objetos audiovisuais podem ser abordados além de seus elementos semiológicos ou estéticos, serão tomados como um objeto cultural com existência e sentido num determinado momento histórico. Eles materializam traços de seu tempo e autoriza uma abordagem sócio-histórica (FERRO, 2010).

Nessa linha de preocupação, pensamos que a reflexão sobre a ciência como instrumento de desenvolvimento da sociedade e a cultura como instrumento de afirmação identitária pode ser relacionada à leitura e interpretação de diversos objetos culturais. Norteados pela questão motriz de quais são as contribuições da população africana e afrodescendente para a transformação científica e social de nossa sociedade, escolhemos seis objetos materializados nas linguagens verbal, visual e audiovisual.

Seguindo os critérios de causar impacto e motivar os educandos do Ensino Fundamental II da escola pública, pensamos ser relevante articular as diversas linguagens, os diversos suportes e as diversas culturas.

Com a finalidade de apresentar o tema transversal da pluralidade cultural e sensibilizar os educandos, sugerimos o vídeo clip e, posteriormente, a letra da música Black gold, interpretada por Speranza Spalding. Para esse momento, a leitura e interpretação desse vídeo pode levantar questões diretamente ligadas à língua inglesa na oralidade e na tradução do título e da letra, à presença e inclusão da população negra ao redor do mundo e no Brasil, à caracterização do suporte vídeo e sua linguagem própria, aos dados biográficos da intérprete, entre outras. O videoclipe selecionado tem uma linguagem mista entre uma narrativa cotidiana de pessoas negras e a música em si. Speranza Spalding ocupa o lugar de fala da mulher jovem negra que reafirma os valores de sua cultura e posicionamento político pela equidade civil e histórica, constituindo em mais um elemento a ser trabalhado pelo gênero da biografia da cantora norte-americana. Assim sendo, paralelamente, o trabalho com a letra da música Black Gold acrescenta elementos identitários e contribui para refletir sobre a pluralidade cultural no cotidiano escolar.

Após o momento inicial de impacto e instigação, o trabalho com o hipertexto da revista Super Interessante, a matéria “Os dez maiores inventores e cientistas negros da 
história", assinada por Leandro Saionete, pode colaborar para mostrar a relevância de estudar a presença dos negros nos diversos âmbitos sociais, bem como mapear as principais características dos gêneros jornalístico e hipermidiático. $O$ texto da revista apresenta as linguagens verbal e visual e o suporte hipermidiático, amplia o conhecimento científico e reivindica um outro lugar histórico para africanos e afrodescendentes. Ao listar cientistas negros, a matéria mostra outro lugar possível para meninos e meninas negros no âmbito das pesquisas científicas e na produção de saberes.

$\mathrm{Na}$ sequência, articulando o poder de simulação da realidade do cinema e dos elementos sociais do filme Black Panther (traduzido no Brasil como Pantera Negra, dirigido por Rayan Coogler, EUA, 2018), podem ser explorados na leitura e interpretação do filme a discussão das especificidades da linguagem cinematográfica, os diversos gêneros discursivos presentes no suporte e aqueles evocados por sua existência, as relações étnico-raciais, a presença dos negros em todas as esferas sociais e os elementos sócio-históricos e artísticos.

O filme hollywoodiano escolhido, a despeito de seus objetivos mercadológicos e do simplismo na narrativa, pode contribuir para pensar o tema transversal por mostrar personagens negros em uma sociedade avançada. Para a leitura e interpretação do filme é importante sua decomposição em elementos como o idioma original e a legendagem; a trajetória cinematográfica do diretor, roteirista, produtor e distribuidor; a classificação de gênero; a trilha sonora e o uso de cores entre outros. Depois, é necessário fazer o movimento de perceber como esses diversos elementos são ordenados na produção do sentido do filme como um todo. Isso está em consonância com a visão de Napolitano (2013, p. 57) de que "Boa parte dos valores e das mensagens transmitidas pelos filmes a que assistimos se efetiva não tanto pela história contada em si, e sim pela forma de contá-las."

Como nos demais filmes americanos, no Black Panther, "o principal agente causal é, portanto, o personagem, um indivíduo distinto dotado de um conjunto evidente e consistente de traços, qualidades e comportamentos (BORDWELL, 2004, p. 279). É nesse ponto que se destaca uma diferenciação, trata-se de um herói negro. Uma atmosfera de realidade 
produz a narrativa fílmica e faz parecer que é o próprio mundo que se dá a ver (XAVIER, 2005). Esse é um poderoso recurso que envolve, sensibiliza e emociona o público e pode ser explorado para além de seus recursos estéticos, na direção de trabalhar elementos identitários e culturais dos afrodescendentes, especialmente da população brasileira.

Fazendo um deslocamento para o âmbito brasileiro, convocamos a "poetisa preta", Carolina Maria de Jesus, (1914-1977), com “Sonhei”. Numa produção tramada no sofrimento e no sonho, é destacada a necessidade de igualdade civil e fim do racismo, finalizando com o verso “Quero um lugar, onde o preto é feliz". Mais um objeto cultural que situa e valoriza a produção de pessoas negras, colocando em pé de igualdade as etnias que compõem nossa sociedade.

Por fim, o trabalho com a imagem de "I have a dream", de Martin Luther King Jr. no pavimento do Lincon Memorial, nos Estados Unidos pode possibilitar a leitura e a análise do visual, a produção de sentidos em diferentes suportes, assim como conhecer a biografia de outro homem ilustre da história mundial.

Nesse contexto, pensamos ser produtivo o exercício de produção textual, visual e audiovisual, bem como os processos de revisão das produções, apresentação para a comunidade escolar e avaliação dos resultados como intervenção no microcosmo da sala, da escola e da sociedade conectada. A relevância da sequência didática se desdobra do conteúdo para a participação em práticas sociais marcadas pelo reconhecimento da pluralidade cultural e da contribuição de africanos e afrodescendentes para o desenvolvimento social.

Paralelamente, com esses objetos culturais pretende-se estimular o estudo de questões ligadas à nossa sociedade, mais especificamente da população africana e afrodescendente e o debate numa perspectiva ativa no processo de aprendizagem, para além de elementos folclóricos ou anedóticos, como nas datas comemorativas do dia do folclore e da consciência negra.

Não se trata da simples leitura ou exibição de objetos culturais em sala de aula, mas de buscar compreender sua constituição como gênero, numa perspectiva sobre fatos e representações a partir da visão sociointeracionista do processo de ensino-aprendizagem. 
Consideramos que as análises exigem preparação por parte de discentes e docentes a fim de possibilitar que esses objetos sejam didatizados.

Nessa linha de preocupação, Moran (1995, p. 27) assevera que “o vídeo ajuda a um professor, atrai os alunos, mas não modifica substancialmente a relação pedagógica". É necessário repensar as velhas práticas e implementar novas práticas para estimular a criatividade dos envolvidos, desenvolver a criticidade, facilitar a compreensão dos conteúdos e aguçar a curiosidade, o interesse dos educandos e a sensibilização para outras realidades. Do mesmo modo, é crucial identificar suas representações e problematizá-las como superfície de valores sociais e históricos. O caminho didático pode partir das imagens para o mundo que as produz e voltar para o presente como ponto de compreensão dos sujeitos.

Salientamos, pois, o potencial provocador das linguagens visual e audiovisual no contexto pedagógico. Com efeito, é importante aprender a ler as mídias em seus contextos de produção e circulação para uma apropriação efetiva da língua, dos objetos culturais e dos gêneros na sala de aula.

\section{"E dêixo êstes versos ao meu país"}

Baseando nos pressupostos teóricos discutidos nessas páginas e da proposta de atividade, podemos afirmar que o cenário do mundo conectado e da sociedade da informação coloca as novas tecnologias e os gêneros discursivos no cotidiano dos educandos e convoca os professores a repensarem os recursos didáticos, as teorias e as práticas pedagógicas. Especificamente, o aparecimento de novos objetos e novas tecnologias tem como consequência a criação de novos gêneros discursivos como processo natural de transformação na linguagem humana. Observamos, ainda, que seu reconhecimento pela inclusão nas práticas didáticas permite, igualmente, a inclusão dos novos sujeitos moldados pelas mesmas. 
Ademais, como argumentam Bakhtin (2003) e Bronckart (1999), conhecer as diversas linguagens e os diversos gêneros contribui significativamente para a efetiva inserção dos alunos tanto na língua como na sociedade.

A educação escolar do século XXI é tensionada para abarcar os temas que emergem das situações do cotidiano dos educandos por meio de abordagens transversais e interdisciplinares, para transformar a sociedade em um lugar mais igualitário e inclusivo para todos, em especial para as minorias representativas da sociedade brasileira.

Centrando na proposta de sequência didática, podemos afirmar que o diálogo entre a teoria e o cotidiano escolar permite uma visão mais aberta para as linguagens, suas particularidades e suas potencialidades com a finalidade de sensibilizar, contextualizar, exemplificar e a ilustrar conteúdos.

Finalizando, acreditamos que é possível oferecer uma aprendizagem estimulante e motivadora para alunos nos diversos níveis escolares, relacionando o estudo de gêneros discursivos, diversas linguagens e temas relevantes para a realidade dos estudantes. Os versos de Carolina Maria de Jesus, que nos acompanharam desde a epígrafe até aqui, podem ilustrar a vontade de conhecer e de ter sua existência reconhecida - "Para amenizar meu sofrimento" - da população afrodescendente, em um país multicultural e racista. Continuamos a sonhar com "um lugar onde o preto [e todos] é feliz".

\title{
AUDIOVISUAL LANGUAGE IN THE CLASSROOM: NEW SUBJECTS, NEW OBJECTS AND NEW PRACTICES
}

\begin{abstract}
In this study, we aim, firstly, to propose the study of verbal, visual and audiovisual languages in school context and their comprehension as a cultural surface that gives visibility to other existences and other worlds. From this objective, we designed this specific objectives: map potentialities and limitations of audiovisual as a pedagogical resource; identify in which pedagogical perspectives this practice can occur; offer elements to understand possibilities of using audiovisual in the classroom; and elaborate a pedagogical sequence proposal that addresses discursive genres and ethnic-racial relations for Elementary School classroom. Focusing on the proposal of pedagogical sequence, we can say that the dialogue between theory and daily school life allows a more open view to languages, their particularities and their potentialities in order to raise awareness, contextualize, exemplify and illustrate contents.
\end{abstract}


KEYWORDS: Audiovisual language; Discursive genres; Ethnic-racial relations; Pedagogical sequence.

\section{REFERÊNCIAS}

BAKHTIN, Mikhail. (VOLOCHINOV, V. N.) Marxismo e filosofia da linguagem. Tradução de M. Lahude Y. F. Vieira. 8. ed. São Paulo: Hucitec, 1997.

BAKHTIN, Mikhail. Estética da criação verbal. 4. ed. Tradução de P. Bezerra. São Paulo: Martins Fontes, 2003.

BORDWELL, David. O cinema clássico hollywoodiano: normas e princípios narrativos. em: RAMOS, Fernão Pessoa (Org.). Teoria contemporânea do cinema: documentários e narrativa ficcional. São Paulo: Senac São Paulo, 2004. p. 277-301.

BRASIL. Parâmetros Curriculares Nacionais: Terceiro e quarto ciclos do Ensino Fundamental: Língua Estrangeira. Brasília: MEC/SEF, 1998.

BRASIL. Parâmetros curriculares nacionais: introdução aos parâmetros curriculares nacionais. Brasília: MEC/SEF, 1997.

BRONCKART, Jean Paul. Interacionismo Sócio-discursivo: uma entrevista com Jean Paul Bronckart. Revista Virtual de Estudos da Linguagem - ReVEL. Vol. 4, n. 6, março de 2006. Tradução de Cassiano Ricardo Haag e Gabriel de Ávila Othero.

BRONCKART, J.P. Atividades de linguagem, textos e discursos: por um interacionismo sóciodiscursivo. São Paulo: EDUC, 1999.

CHEVALLARD, Yves. La transposition didactique. Du savoir savant au savoir enseigné. Grenoble: La Pensée Sauvage, 1991.

DUDLEY-EVANS, T.; ST. JOHN, M. J. Developments in English for specific purposes: a multi-disciplinary approach. Nova York: Cambridge University Press, 1998.

FERRO, Marc. Cinema e bistória. São Paulo: Paz e Terra, 2010.

FOUCAULT, Michel. A arqueologia do saber. Tradução de L. F. B. Neves. 7 ed. Rio de Janeiro: Forense Universitária, 2007.

GUIMARÃES, Reinaldo; BARLETTE, Vania; GUADAGNINI, Paulo Henrique. A engenharia didática da construção e validação de sequências de ensino: um panorama com foco no ensino de ciências. Revista Polyphonía, v. 26, n.1, jan.-jun. 2015.

HUTCHINSON, T.; WATERS, A. English for specific purposes: a learning centred approach. Cambridge: Cambridge University Press, 1987. 
KLEIMAN, Ângela B. Preciso ensinar o letramento? Não basta ensinar a ler e a escrever? Campinas , UNICAMP/MEC, 2005.

KOBASHIGAWA, A.H.; ATHAYDE, B.A.C.; MATOS, K.F. de OLIVEIRA; CAMELO, M.H.; FALCONI, S. Estação ciência: formação de educadores para o ensino de ciências nas séries iniciais do ensino fundamental. In: IV Seminário Nacional ABC na Educação Científica. São Paulo, 2008. p. 212-217. Disponível em: <http:/ /www.cienciamao.usp.br/dadossmm_estacaocienciaformacaodeeducadoresparaoensinodecienciasnasseriesiniciaisdoensinofundamental.trabalho.pdf>. Acesso em: 22 ago. 2019.

MACHADO, A.R. A transposição do conhecimento científico para o contexto de ensino: a necessidade e as dificuldades. In: Seminário Critérios de avaliação de livros didáticos $5^{a}$ a $8^{a}$ séries. Brasília: Ministério da Educação e de Desporto. 1997. Mimeo.

MARCUSCHI, Luiz Antônio. Produção textual, análise de gêneros e compreensão. São Paulo: Parábola Editorial, 2008.

MORAN, José Manoel. O vídeo na sala de aula. Comunicação \& Educação. Ed. Moderna, [2]: 27-35. São Paulo, 1995. Disponível em: <http://www.revistas.usp.br/comueduc/article/view/36131>. Acesso em: 22 ago. 2019.

MORAN, José Manoel; MASETTO, Marcos Tarciso; BEHRNS, Marilda Aparecida. Novas tecnologias e mediação pedagógica. Campinas: Papirus, 2006.

NAPOLITANO, Marcos. Como usar o cinema na sala de aula. São Paulo: Contexto, 2013.

NASCIMENTO, E. L. Gêneros da atividade, gêneros textuais: repensando a interação em sala de aula. In: - (org.). Gêneros textuais: da didática das línguas aos objetos de ensino. São Carlos: Editora Claraluz, 2009.

RUCKER, Joseane. De olhos bem abertos: uma proposta de sequência didática, aplicada ao design, para o desenvolvimento da autoria na produção textual. Educere et Educare. UNIOESTE. v. 13, jul.-dez.2017.

SANTOS, Paulo Ricardo dos; KLOSS, Sheila. A criança e a mídia: a importância do uso do vídeo em escolas de Joaçaba - SC. Intercom - XI Congresso da Comunicação na Região Sul, Novo Hamburgo, RS, 2010. Disponível em: <https://www.intercom.org.br/papers/regionais/sul2010/resumos/R20-0957-1> Acesso em: 22 ago. 2019.

SILVA, Marco. Sala de aula interativa. Rio de Janeiro: Quartet, 2000.

I HAVE a dream. Disponível em: < https://brasilescola.uol.com.br/historiag/martinluther-king.htm>. Acesso em: 22 ago. 2019.

SAIONETE, Leandro. Os dez maiores inventores e cientistas negros da história. Super Interessante: História, Mundo Estranho. Disponível em: <https://super.abril.com.br 
/mundo-estranho/os-10-maiores-inventores-e-cientistas-negros-da-história/>. Acesso em: 22 ago. 2019.

SPALDING, Speranza. Black Gold. Disponível em: < https://www.letras.mus.br/esperanza-spalding/black-gold/>. Acesso em: 22 ago. 2019.

SPALDING, Speranza. Black Gold. Concord Records. Disponível em:

<https://www.youtube.com/watch?v=Nppb01xhfe0>. Acesso em: 22 ago. 2019.

JESUS, Carolina Maria de. Sonhei. Disponível em: < http://www.letras.ufmg.br/literafro/autoras/24-textos-das-autoras/66-carolina-maria-de-jesus-sonhei>. Acesso em: 22 ago. 2019.

XAVIER, Ismail. O discurso cinematográfico: a opacidade e a transparência. São Paulo: Paz e Terra, 2005.

Recebido em: 09/09/2019. Aprovado em: 20/01/2020. 